\title{
R\&D Investment and Matthew Effect in Economic Growth-An Empirical Study Based on Guangdong Province
}

\author{
Zhengyou Peng \\ College of Economics, Jinan University, Guangzhou, China \\ Email: pengzhengyou2016@126.com
}

How to cite this paper: Peng, Z.Y. (2019) R\&D Investment and Matthew Effect in Economic Growth-An Empirical Study Based on Guangdong Province. Modern Economy, 10, 973-985.

https://doi.org/10.4236/me.2019.103065

Received: February 25, 2019

Accepted: March 23, 2019

Published: March 26, 2019

Copyright $\odot 2019$ by author(s) and Scientific Research Publishing Inc. This work is licensed under the Creative Commons Attribution International License (CC BY 4.0).

http://creativecommons.org/licenses/by/4.0/

\section{(c) (i) Open Access}

\begin{abstract}
This paper uses the panel data of 21 cities in Guangdong Province from 2005 to 2015 to construct a panel data model, and empirically analyzes the impact of local R\&D investment on economic growth from two dimensions: spatial differentiation and time series. The results show that the total social R\&D investment in Guangdong Province has a significant positive impact on economic growth; the impact of R\&D investment on economic growth in the more developed regions (Pearl River Delta) and the less developed regions (other cities in Guangdong) is different. The former is twice as large as the latter, and there are obvious inter-regional differences. From the perspective of time, the gap is increasing, that is, there is a "Matthew effect". It is better for latter to invest more in infrastructure construction, resource environmental protection, special industry cultivation and human resource development than continuing to increase $R \& D$ investment.
\end{abstract}

\section{Keywords}

R\&D, Economic Growth, Regional Differences, Matthew Effect

\section{Introduction}

With the advent of the era of knowledge-based economy, the importance of innovation has become increasingly prominent. The ability of scientific and technological innovation has increasingly become an important factor to measure a country's comprehensive strength. Since the report of the Eighteenth National Congress of the Communist Party of China put forward the "Innovation-driven development strategy", China has stepped up the pace of scientific and technological innovation and strived to gain a more active position in the increasingly 
fierce international competition. Guangdong can be said to be the frontier of China's reform and innovation. As early as in the period of reform and opening up, Guangdong was the earliest batch of experimental sites. In recent years, under the background of the "One belt and One way" strategy, "Guangdong, Hongkong and Macau" and "Guangdong free trade zone" have repeatedly highlighted Guangdong's important position in the new round of reform and innovation. Therefore, it is necessary to conduct in-depth research on Guangdong's innovation and development. The core element of scientific and technological innovation is $\mathrm{R} \& \mathrm{D}$ activities. With the advent of the "double innovation" boom, $\mathrm{R} \& \mathrm{D}$ investment costs in Guangdong are also increasing year by year. So, in Guangdong, is it applicable for all regions to increase R\&D investment intensity? Will there be differences among regions with different levels of development? Or even the "Matthew effect" of the widening gap between the benefits of $R \& D$ investment in developed areas and those in backward areas? To solve these problems is of great practical significance for the future development of Guangdong. Therefore, according to the above-mentioned theoretical background and practical environment, this paper combines R\&D investment with economic growth, discusses the effect of R\&D investment on economic growth, and selects urban level data for research and analysis. To a certain extent, it can fill and perfect the existing research on regional economic development, has certain theoretical value and practical significance.

The article is organized as follows: 1) Introduction. 2) Journals reviewed. 3) The measurement model setting and data description. 4) Empirical analysis. 5) Conclusion and policy implications.

\section{Literature Review}

There have been many studies on the relationship between R\&D investment and economic growth, which can be distinguished mainly from macro and micro aspects. First, from a macro level, Griliches confirmed that there is a positive correlation between R\&D investment and economic growth [1]. Lichtenberg used relevant data to study the differences between national R\&D expenditures and economic growth. The results show that the difference in productivity between countries is largely due to the difference in the number of scientists and engineers and the differences between $R \& D$ expenditures [2]. Charles analyzed the relevant data of 10 important OECD countries and found that R\&D investment significantly promoted the growth of total factor productivity. Similarly, domestic scholars have done many similar studies on the relationship between them [3]. Fangyuan Lu used panel models to study the long-term and short-term effects of R\&D inputs on economic development based on data from 30 provinces across the country. A comparative analysis of the output elasticity of $R \& D$ personnel input and R\&D expenditure [4]. Lanyun Xie used data from 1978 to 2007 to conclude that $R \& D$ expenditures have a lagging and positive effect on China's economic growth, while both R\&D stocks and R\&D flows have a posi- 
tive impact on economic growth [5]. Jianchun Shao et al. used the VAR model to study the long-term equilibrium relationship between $R \& D$ investment and economic growth in China, and believed that there is a long-term stable equilibrium relationship between them, $\mathrm{R} \& \mathrm{D}$ investment has a positive effect on economic growth, and there is a time lag in the promotion of $R \& D$ investment to economic growth [6]. Secondly, from the micro level, Akira Goto et al. studied the impact of R\&D investment on Japanese manufacturing productivity, and calculated that the marginal rate of return on R\&D investment was about $40 \%$ [7]. Jingyu Lu used the relevant data of industrial enterprises above designated size in Shandong Province from 2002 to 2010 to study the regional differences between R\&D investment and economic growth in Shandong Province, and analyzed the differences in the effects of R\&D inputs on economic growth in different regions. And in areas where $R \& D$ investment is high, $R \& D$ investment will positively promote economic growth, while R\&D investment in low-input areas will be less resilient to economic growth [8].

At the same time, the measurement and evaluation of $R \& D$ investment performance is also the focus of many scholars. Using data from US companies, Scherer confirmed that corporate $\mathrm{R} \& \mathrm{D}$ investment will improve innovation performance, indicating a linear positive correlation between $\mathrm{R} \& \mathrm{D}$ input and innovation output [9]. Qinmei Wang et al. regarded the contribution of R\&D investment in economic growth as the sum of the three effects, and analyzed the dynamic impact of R\&D investment on economic growth by logarithmic mean Dirich's index decomposition (LMDI). The results showed the total R\&D input. The impact on economic growth is the most important, and the change in $\mathrm{R} \& \mathrm{D}$ input structure has a positive effect on economic growth, but the impact is small, and $R \& D$ intensity has a significant effect on the economy [10]. Yanbing Wu conducted research on relevant data of manufacturing industry and found that R\&D investment has a significant role in promoting the total factor productivity of China's industries and industries [11]. Wen Pang et al. used the factor analysis method to study the R\&D investment of colleges and universities nationwide. It is empirically concluded that the regional differences in the $\mathrm{R} \& \mathrm{D}$ input and output benefits of colleges and universities are large, and the basic research of colleges and universities plays an important role in economic growth [12]. Jianping Peng used the dynamic panel data model to conduct research and analysis on China's provinces and cities except Tibet, and found that China's R\&D input and output elasticity is significant. Every $1 \%$ increase in R\&D investment stock will increase GDP by 0.096 to 0.106 percentage points [13].

It can be seen from the above that the relationship between $R \& D$ investment and economic growth has always been a key issue in the field of economics, and a large number of existing studies have confirmed that R\&D investment has a positive impact on economic growth. In addition, through the combing of the literature, we can find that Chinese scholars use different research methods and models because of different research perspectives and ideas, and the different 
samples and data are different, resulting in different conclusions. On the basis of consulting a certain amount of literature, this paper finds that most scholars' research on the relationship between R\&D investment and economic growth can be summarized into the following categories. Some scholars analyze the impact on economic growth from the total R\&D expenditure, and some of them analyze from the different structures of expenditure, others analyze from the impact of $\mathrm{R} \& \mathrm{D}$ inputs to total factor productivity, and the impact of $\mathrm{R} \& \mathrm{D}$ inputs on innovation output.

For the regional differences, Chinese scholars have also done more analysis. Zhongxian Cao et al. used the relevant panel data of 110 cities in the Yangtze River Economic Belt to analyze the impact of $\mathrm{R} \& \mathrm{D}$ expenditures and personnel input on regional economic growth. The results show that the economic growth and $\mathrm{R} \& \mathrm{D}$ investment in the Yangtze River Economic Belt have long-term in terms of stable relationship, R\&D personnel's input and output elasticity is higher than $R \& D$ expenditure, and $R \& D$ investment shows that the eastern region is higher than the central region, and the central region is higher than the western region. However, the impact of $\mathrm{R} \& \mathrm{D}$ investment on regional economic growth is greater in the central and western regions than in the east [14]. Ling Yu et al. used the data of national R\&D input intensity from 2002 to 2012 to divide the country into R\&D high-input, medium-input, low-input areas, and used the fixed-effect variable coefficient model to obtain $R \& D$ inputs in different $R \& D$ input intensity regions. Regarding the different degrees of economic growth, R\&D high-input and low-input regions have a greater role in promoting economic growth, and medium-investment regions have a more stable effect on the economy [15]. Wei Feng analyzed the panel data of 31 provinces in China, and found that regional R\&D investment has different economic growth. R\&D investment has a significant effect on the eastern region's economy. The central and western regions are lack of human resources and they are low degree of opening to the outside. The low level has led to $R \& D$ inputs having a negative impact on economic growth in the region [16].

Although Chinese scholars have made a lot of analysis on the regional differences in $R \& D$ investment, many conclusions have been drawn from the reference. However, most scholars use data from various provinces and cities in the country, the research on a more specific region is relatively few, and most of them only analyze the existence of regional differences, there are few analytical studies on some subsequent time trends. This paper selects Guangdong Province as the research object, and attempts to explore whether there is a difference in the R\&D investment effect between Guangdong's economically developed regions and economically backward regions. Will this difference change over time, resulting in a "Matthew effect" between the two regions?

The word "Matthew Effect" is derived from a parable in the Bible. Robert K. Merton, a researcher in the history of the United States, has scientifically interpreted that any individual, group, or region that succeeds and progresses in one 
aspect (such as money, reputation, status, etc.) will have an accumulated advantage. There will be more opportunities for greater success and progress. Foreign studies on Matthew effect are relatively early, and the results are also diverse. For example, Matthew R. Sanderson used nearly 45 years of cross-country data to empirically analyze that international immigrants have different effects on countries with different degrees of development. International income inequality leads to the Matthew effect. However, domestic research on the Matthew effect started late, and there are not many studies in the regional economy [17]. Mingchun Yu et al. used the survey data of 6 flag counties in Bayannaoer City to analyze the production of Matthew in underdeveloped counties. The reason for the effect, and summed up the way to cross the Matthew effect [18]. Jinwen Liu reveals the cause of the Matthew effect in human capital through the study of the flow of human capital between regions [19]. Song Wang et al. taking China's national high-tech zone as the research object, the empirical analysis confirm that the existence of Matthew effect [20].

In summary, the domestic research on Matthew effect pays more attention to the representation of phenomena and mechanisms, and there are few empirical analyses. Among them, the research on whether there is a Matthew effect on $\mathrm{R} \& \mathrm{D}$ investment and economic growth in the regional economy is rare. This article selects Guangdong as the object, not only because of its special innovation status in China, but also because the difference in the degree of development of the cities within Guangdong is obvious, and it can better explain the purpose we want to study. The Pearl River Delta region has strong economic strength and innovation and entrepreneurship centers such as Shenzhen, which are very attractive to talents and resources. Guangdong's eastern and western regions are relatively backward, infrastructure is not perfect, and it is far from the gathering center. Resources are less attractive. In this way, the Pearl River Delta region continues to absorb high-quality resources and improve the level of scientific research, making innovation investment easier to transform into innovative output, thereby gaining advantages and accelerating its own development; while the eastern and western regions of Guangdong are seriously backward due to their economic backwardness, infrastructure Inconvenience, the level of scientific research is low, and the efficiency of transforming innovative inputs into innovative outputs is also low. So this paper presents the first hypothesis:

Hypothesis 1: R\&D investment has different effects on GDP growth between regions with different levels of development.

Second, as time goes by, the economic gap between them will shrink (the backward regions enjoy the advantage of latecomers)? Or is it expanding (there is a Matthew effect)? Many scholars have not reached a consensus. Therefore, this paper proposes a second hypothesis:

Hypothesis 2: Over time, the economic gap between regions with different levels of development due to $R \& D$ investment will gradually widen, that is, there is a "Matthew effect". 
As the largest economic province in China, Guangdong's importance is selfevident. Therefore, this paper takes 21 cities in Guangdong Province as the research object. Starting from the relationship between R\&D investment and GDP, 21 cities are divided into two parts, the economically developed areas (the Pearl River Delta) and the economically backward areas (Guangdong, North and West), to examine the impact of R\&D investment on the GDP of the two regions, and further analyze how the economic gap between the two regions changes.

\section{The Measurement Model Setting and Data Description}

\subsection{Model Setting}

According to the new economic growth theory represented by Romer and Lucas, technological progress is the determinant of sustained economic growth, and an important way of technological progress is $R \& D$ investment. $R \& D$ investment can promote the accumulation of intellectual capital, improve the quality of laborers, and innovate production methods, so that the output can achieve twice the result with half the effort.

$R \& D$ investment mainly includes $R \& D$ expenditure and $R \& D$ personnel input. The focus of this paper is on $R \& D$ expenditure. The relationship between R\&D investment and economic growth is shown in Figure 1.

This paper uses the Cobb-Douglas production function (CD function) as the basic model for analyzing the relationship between R\&D investment and economic growth:

$$
Y=A K^{\alpha} L^{\beta}
$$

where: $Y$ represents total output; $K$ represents input for material capital; $L$ is input for labor; $\alpha$ and $\beta$ representing output elasticity for physical capital and labor; A represent other factors other than labor and capital. Human capital is an important factor affecting economic growth, but due to the lack of data, this article does not consider it. Since this paper mainly discusses the impact of R\&D investment on economic growth, and can not ignore the influence of other factors, so the R\&D investment is first stripped from it. The formula is:

$$
Y=A K^{\alpha} L^{\beta} R^{\gamma}
$$

where $R$ is $R \& D$ investment elements. In order to facilitate regression, the above model is usually transformed into logarithmic form:

$$
\ln Y=\alpha \ln K+\beta \ln L+\gamma \ln R+\ln A
$$

Secondly, because the panel data of 21 cities in Guangdong Province from

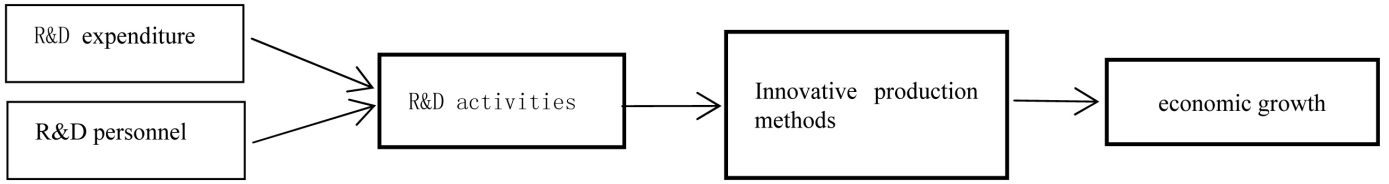

Figure 1. The relationship of R\&D investment and economic growth. 
2005 to 2013 are used in this paper, the panel data model is further established on the basis of formula (3):

$$
\ln Y_{i t}=c_{i}+\alpha_{i} \ln K_{i t}+\beta_{i} \ln L_{i t}+\gamma_{i} \ln R_{i t}+\ln A_{i t}+\varepsilon_{i t}
$$

where $Y_{i t}, K_{i t}, L_{i t}, R_{i t}$ represents the total output, material capital input, labor input and R\&D input of region $I$ in year $t$, respectively. $c_{i}, \varepsilon_{i t}$ represents intercept term and random error term, respectively. $\ln A_{i t}$ represents other influencing factors.

For hypothesis 1 , in order to explore the inter-regional differences in $R \& D$ investment, we rewrite (4) as follows:

$$
\ln Y_{i t}=c_{i}+\alpha_{i} \ln K_{i t}+\beta_{i} \ln L_{i t}+\gamma_{i} \ln R_{i t}+\text { pearl }+\chi \mathrm{RP}_{i t}+\ln A_{i t}+\varepsilon_{i t}
$$

where pearl is a fictitious variable, if the region belongs to the Pearl River Delta, the value is 1 , otherwise 0 ; RP is a multiplier with pearl, and its coefficient reflects the difference of economic growth caused by R\&D investment among regions. Due to the different degree of development in different regions, it is necessary to add appropriate control variables. However, due to the limitation of sample size and data availability, we finally choose urbanization rate (Urb) and marketization degree (Market) as control variables. Modify Formula (5) to the following form:

$\ln Y_{i t}=c_{i}+\alpha_{i} \ln K_{i t}+\beta_{i} \ln L_{i t}+\gamma_{i} \ln R_{i t}+$ pearl $+\chi \mathrm{RP}_{i t}+\delta \mathrm{Urb}_{i t}+\phi$ market $_{i t}+\varepsilon_{i t}(6)$

For hypothesis 2, in order to analyze the change of time trend, we construct the following model:

$\ln Y_{i t}=c_{i}+\alpha_{i} \ln K_{i t}+\beta_{i} \ln L_{i t}+\gamma_{i} \ln R_{i t}+\delta_{i t} \mathrm{Urb}_{i t}+\phi_{i}$ market $_{i t}+$ pearl $+y_{2}+\ldots+y_{11}+\varepsilon_{i t}(7)$

where $y_{j}(j=2 \ldots 11)$ represents $\ln \mathrm{RD} *$ year $_{j} *$ pearl $^{\text {. The variation trend of }}$ its coefficients can reflect the variation trend of interregional differences over time.

\subsection{Data Description}

This paper uses panel data of 21 prefecture-level cities in Guangdong Province from 2005 to 2015 to make an empirical analysis. The variables in the model are set as follows: the real GDP of each city is used to measure regional economic growth $(Y)$; the number of employed people at the end of the year is used to represent labor input $(L)$; and the material capital stock is used to measure the material capital input $(K)$. The Goldsmith (1951) method of perpetual inventory is adopted. The basic formula is as follows:

$$
K_{i t}=I_{i t}+(1-\delta) K_{i t-1}
$$

where $i$ is the region, $t$ is the year; $K$ is the stock of material capital; $I$ is the investment of the year; $\delta$ is the depreciation rate. Referring to the method of calculating capital stock of Jun Zhang et al. (2004), taking 2000 as the base year, the depreciation rate is $10 \%$. Then the annual investment amount is reduced by the fixed assets investment price index, which is converted into the comparable price in 2000. The final result is basically consistent with that of Zhang Jun et 
al.'s calculation of material capital stock in 2000 in Guangdong Province.

For R\&D investment (R), we use R\&D internal expenditure (RD) to express it. Although many scholars believe that R\&D input should be studied in the form of stock is more reasonable, considering the lack of data in Guangdong Province and the rationality of base year selection, we still use the flow data of $R \& D$ input to study.

For the urbanization rate (Urb) and the degree of marketization (market), the ratio of urban population to resident population and the ratio of the total output value of non-state-owned industrial enterprises to the total output value of industrial enterprises are used to replace them.

The above data are from Guangdong Industrial Development Database, Guangdong Science and Technology Statistical Yearbook and Guangdong Statistical Yearbook. Variable measures and their descriptive statistical results are shown in Table 1.

\section{Empirical Analysis}

When performing regression analysis on the panel data model, it is necessary to consider whether to use the fixed effect model or the random effect model. After Hausmann test, it is better to use random effect model. Considering that the model contains variables that are not changing at any time, the random effects model is used to perform regression simultaneously.

\subsection{Regression Result}

First, it is a regression analysis of Hypothesis 1 . The regression results are shown in Table 2.

Model 1 is the most basic regression equation, indicating that R\&D investment does have a significant positive impact on economic growth.

Model 2 is a regression equation for adding control variables. The results show that both the degree of marketization and the rate of urbanization have a

Table 1. Descriptive statistical results of variables.

\begin{tabular}{|c|c|c|c|c|c|c|}
\hline Variables & Measure index & $\operatorname{Max}$ & Min & Mean & Std & Num \\
\hline $\mathrm{GDP}_{i t}$ & Real GDP/billion & $14,507.8$ & 187.8 & 2034.08 & 2743.08 & 231 \\
\hline$K_{i t}$ & Capital stock/billion & $23,961.9$ & 234.48 & 2963.73 & 3758.64 & 231 \\
\hline$L_{i t}$ & $\begin{array}{l}\text { Employment at the end of the } \\
\text { year/ten thousand }\end{array}$ & 906.14 & 94.01 & 272.8 & 185.23 & 231 \\
\hline $\mathrm{RD}_{i t}$ & $\begin{array}{l}\text { Internal expenditure on } \mathrm{R} \& \mathrm{D} \\
\text { funds/billion }\end{array}$ & 722.8 & 0.04 & 43.31 & 101.58 & 231 \\
\hline market $_{i t}$ & $\begin{array}{l}\text { Marketization Degree (The } \\
\text { proportion of non-state-owned } \\
\text { industrial output value to industrial } \\
\text { output value) }\end{array}$ & 0.965 & 0.288 & 0.806 & 0.154 & 231 \\
\hline $\mathrm{Urb}_{i t}$ & $\begin{array}{l}\text { Urbanization Rate (Percentage of } \\
\text { Urban Population to Permanent } \\
\text { Resident Population) }\end{array}$ & 1 & 0.324 & 0.608 & 0.202 & 231 \\
\hline
\end{tabular}


Table 2. Result of hypothesis 1 .

\begin{tabular}{|c|c|c|c|}
\hline variables & Model 1 & Model 2 & Model 3 \\
\hline $\ln K_{i t}$ & $0.6660543^{* * *}(22.16)$ & $0.6256402^{* * *}(21.13)$ & $0.626234^{\star * *}(20.96)$ \\
\hline $\ln L_{i t}$ & $0.4995389^{\star * *}(7.81)$ & $0.4841839^{* * *}(7.94)$ & $0.4257775^{\star * \star}(6.18)$ \\
\hline $\ln \mathrm{RD}_{i t}$ & $0.0351481^{\star * *}(2.62)$ & $0.0408793^{* * *}(3.2)$ & $0.0470211^{\star * *}(3.56)$ \\
\hline market $_{i t}$ & & $0.5169104^{* * *}(4.22)$ & $0.5772896^{\star \star \star}(4.65)$ \\
\hline $\mathrm{Urb}_{i t}$ & & $0.004162^{* * *}(2.74)$ & $0.0033325^{\star *}(1.96)$ \\
\hline pearl & & & $0.0342138(0.4)$ \\
\hline $\mathrm{RP}$ & & & $0.0306848^{* *}(2.11)$ \\
\hline
\end{tabular}

Note: Coefficients with $z$-scores in parentheses. ${ }^{*} \mathrm{p}<0.1,{ }^{* *} \mathrm{p}<0.05,{ }^{* * *} \mathrm{p}<0.01$.

significant positive impact on economic growth. Specifically, for every $1 \%$ increase in marketization, GDP will increase by about $0.52 \%$. For every $1 \%$ increase in urbanization rate, GDP will increase by about $0.04 \%$.

Model 3 introduces the regional dummy variable pearl. We can see that the $\mathrm{RP}$ coefficient is significantly positive, indicating that there is a difference in the impact of R\&D investment on inter-regional economic growth. Specifically, for every $1 \%$ increase in $\mathrm{R} \& \mathrm{D}$ investment in the eastern and western regions of Guangdong, GDP will increase by $0.047 \%$. For every $1 \%$ increase in R\&D investment in the Pearl River Delta region, GDP will increase by about $0.081 \%$. Roughly speaking, the growth effect of the latter's R\&D investment on GDP is twice that of the former, and the inter-regional differences are significant.

Second, it is a regression analysis of Hypothesis 2. The regression results are shown in Table 3. The results show that from the perspective of time trend, the growth effect of R\&D investment in the Pearl River Delta and Guangdong North and West on GDP will have a polarization effect with time. Specifically, the coefficient of $y_{2}-y_{11}$ is getting larger and larger as a whole, increasing from 0.0127 to 0.0245 , almost doubled; since the time corresponding to $y_{2}$ is 2006 , we can see that the coefficient of $y_{5}$ (2009) has decreased. This may be due to the financial crisis in 2008, which led to a decrease in the efficiency of R\&D investment in economic growth. The Pearl River Delta region is more affected by the economic development and more dependent on the innovative economic development mode. The gap has narrowed in the short term and then gradually widened. From the above analysis, we can conclude that the growth effect of R\&D investment between the Pearl River Delta and Guangdong and North East on GDP will show a polarization effect of "the stronger the stronger, the weaker the weaker", there is "Matthew effect".

\subsection{Robustness Test}

In this paper, the R\&D personnel's full-time equivalent is used to replace the internal expenditure of R\&D expenditure, and the appeal regression is repeated. The results are shown in Table 4 and Table 5. It can be seen from Table 4 that 
Table 3. Result of hypothesis 2.

\begin{tabular}{cccc}
\hline variable & coefficient & variable & coefficient \\
\hline $\ln K_{i t}$ & $0.6300106^{* * *}(20.42)$ & $y_{4}$ & $0.0251284^{\star}(1.82)$ \\
$\ln L_{i t}$ & $0.3615595^{* * *}(4.36)$ & $y_{5}$ & $0.0166476(1.27)$ \\
$\mathrm{RD}_{i t}$ & $0.0322223^{* *}(2.5)$ & $y_{6}$ & $0.0213323^{\star}(1.71)$ \\
market $_{i t}$ & $0.6632099^{* * *}(5.15)$ & $y_{7}$ & $0.0206584^{*}(1.76)$ \\
$\mathrm{Urb}_{i t}$ & $0.0031311^{*}(1.71)$ & $y_{8}$ & $0.0237938^{* *}(2.09)$ \\
pearl & $0.0312767(0.29)$ & $y_{9}$ & $0.0247107^{* *}(2.20)$ \\
$y_{2}$ & $0.0126857(0.8)$ & $y_{10}$ & $0.0254633^{* *}(2.28)$ \\
$y_{3}$ & $0.0197316(1.35)$ & $y_{11}$ & $0.0245396^{* *}(2.23)$
\end{tabular}

Note: Coefficients with $z$-scores in parentheses. ${ }^{*} \mathrm{p}<0.1,{ }^{* *} \mathrm{p}<0.05,{ }^{* * *} \mathrm{p}<0.01$.

Table 4. Robustness test of hypothesis 1.

\begin{tabular}{|c|c|c|c|}
\hline variables & Model 1 & Model 2 & Model 3 \\
\hline $\ln K_{i t}$ & $0.6747489^{* * \star}(24.84)$ & $0.6435994^{* * *}(24.14)$ & $0.6400252^{\star * \star}(23.53)$ \\
\hline $\ln L_{i t}$ & $0.4846917^{\star * \star}(7.54)$ & $0.4714145^{\star * \star}(7.72)$ & $0.413828^{\star * *}(5.98)$ \\
\hline $\ln P_{i t}$ & $0.0391825^{* * *}(2.65)$ & $0.0411205^{\star * *}(2.91)$ & $0.0515978^{\star * *}(3.37)$ \\
\hline market $_{i t}$ & & $0.4994513^{* * *}(4.08)$ & $0.5629649^{\star * \star}(4.51)$ \\
\hline $\mathrm{Urb}_{i t}$ & & $0.0039153^{* * *}(2.58)$ & $0.0030646^{\star}(1.80)$ \\
\hline pearl & & & $0.0247092(0.29)$ \\
\hline PP & & & $0.0377511^{\star *}(2.03)$ \\
\hline
\end{tabular}

Note: Coefficients with $z$-scores in parentheses. ${ }^{*} \mathrm{p}<0.1,{ }^{* *} \mathrm{p}<0.05,{ }^{* * *} \mathrm{p}<0.01$.

Table 5. Robustness test of hypothesis 2 .

\begin{tabular}{|c|c|c|c|}
\hline variables & coefficient & variable & coefficient \\
\hline $\ln K_{i t}$ & $0.6397854^{\star * *}(23.16)$ & $z_{4}$ & $0.0091158^{\star}(1.89)$ \\
\hline $\ln L_{i t}$ & $3394519^{* * *}(4.18)$ & $z_{5}$ & $0.0067353(1.41)$ \\
\hline $\ln P_{i t}$ & $0.0326924^{\star *}(2.34)$ & $z_{6}$ & $0.009616^{\star *}(2.01)$ \\
\hline market $_{i t}$ & $0.6599309^{\star * *}(5.15)$ & $z_{7}$ & $0.0101909^{\star *}(2.15)$ \\
\hline $\mathrm{Urb}_{i t}$ & $0.0028343(1.71)$ & $z_{8}$ & $0.0113945^{\star *}(2.42)$ \\
\hline pearl & $0.0244181(0.22)$ & $z_{9}$ & $0.0127323^{* * *}(2.66)$ \\
\hline$z_{2}$ & $0.0036644(0.74)$ & $z_{10}$ & $0.0128065^{\star * *}(2.68)$ \\
\hline$z_{3}$ & $0.0068778(1.41)$ & $z_{11}$ & $0.0121265^{\star *}(2.55)$ \\
\hline
\end{tabular}

Note: Coefficients with $z$-scores in parentheses. ${ }^{*} \mathrm{p}<0.1,{ }^{* *} \mathrm{p}<0.05,{ }^{* *} \mathrm{p}<0.01$.

whether the R\&D investment is used or the full-time equivalent of the $R \& D$ personnel, the regression results are basically the same, and the regression coefficients of each variable and the significance change are small. The variability and coefficient variation of each variable in Table 5 are also small, and the overall trend of the coefficient before the variable $(z)$ representing the time trend is 
gradually increasing. Therefore, the empirical results of this paper can be considered to be relatively stable. That is, between regions with different levels of development, R\&D investment has different effects on GDP growth. Developed regions are about twice as large as backward regions, and as time goes by, this difference will gradually expand, forming a stronger and weaker In the weaker case, there is a "Matthew effect."

\section{Conclusions and Policy Implications}

Since the 18th National Congress put forward the "innovation-driven development strategy", all regions of the country are scrambling to increase investment in innovation and expect to achieve their own rapid development. It is undeniable that the role of innovation investment in economic growth is remarkable, the most typical is Shenzhen. However, when the whole country is investing in the "double innovation" boom, people often overlook the regional differentiation caused by the unbalanced development between regions, and this difference has a very important impact on the economic development mode of different regions. This paper uses the panel data of 21 prefecture-level cities in Guangdong Province from 2005 to 2015 to construct a panel model, and empirically analyzes the differences in the growth effect of R\&D investment on GDP between regions with different economic development degrees in Guangdong Province, namely inter-regional differences. Significantly; secondly, by analyzing the time trend, it shows that the inter-regional difference will gradually expand with time, and finally form the Matthew effect of "the stronger the stronger, the weaker the weaker".

Then, in the context of "innovation-driven development strategy", how should Guangdong achieve regional economic development better? From the above analysis, we can draw the following enlightenment: due to historical reasons, their own resource endowments, location conditions, etc., there are different degrees of economic development, which leads to significant differences in the efficiency of R\&D investment. Backward areas blindly follow the trend, like the developed regions, blindly increase the intensity of $R \& D$ investment, which will result in improper resource allocation and inefficient R\&D investment. Therefore, the relevant government departments should rationally treat whether to increase the intensity of $R \& D$ investment to promote their own development. Guangdong's eastern and western regions can develop local characteristic industries according to their own conditions, strengthen infrastructure construction, actively undertake industries that have been migrated due to industrial transformation and upgrading in the Pearl River Delta region, form dislocation development, and use late-comer advantages to achieve rapid economic growth. In addition, both the degree of marketization and the rate of urbanization have a significant role in promoting economic growth. The eastern and western regions of Guangdong have yet to be strengthened in these areas. The relevant government can relax the conditions for the entry of non-state-owned enterprises, give 
certain preferential policies, and also attach importance to The reform of the household registration system will attract funds and talents and enhance their economic strength.

\section{Conflicts of Interest}

The author declares no conflicts of interest regarding the publication of this paper.

\section{References}

[1] Griliches, Z. (1986) Productivity, R\&D, and Basic Research at the Firm Level in the 1970s. American Economic Review, 76, 141-154.

[2] Lichtenberg, F.R. (1992) R\&D Investment and International Productivity Differences. National Bureau of Economic Research. https://doi.org/10.3386/w4161

[3] Jones, C.I. (1998) Growth: With or without Scale Effect. American Economic Review, 89, 139-144.

[4] Lu, F. (2011) The Impact of China's R\&D Investment on Economic Growth-An Empirical Analysis Based on Panel Data. China Industrial Economics, 3, 149-157.

[5] Xie, L. (2009) Econometric Analysis of the Relationship between R\&D Investment and Economic Growth in China. Dongbei University of Finance and Economics, Dalian.

[6] Shao, J. and Li, X. (2008) R\&D Investment and China's Economic Growth: Research Based on VAR Model. Economic Issues, 5, 45-47.

[7] Goto, A. and Suzuki, K. (1989) R\&D Capital, Rate of Return on R\&D Investment and Spillover of R\&D in Japanese Manufacturing Industries. Review of Economics \& Statistics, 71, 555-564. https://doi.org/10.2307/1928096

[8] Lu, J. (2012) Research on the Differences of Regional R\&D Inputs on Economic Growth in Shandong Province. Shanghai Academy of Social Sciences, Shanghai.

[9] Scherer, F.M. (1965) Firm Sizes, Market Structure, Opportunity and the Output of Patented Innovations. American Economic Review, 55, 1097-1125.

[10] Wang, Q., Yin, P. and Yao, Y. (2011) An Empirical Study on the Relationship between R\&D Input and Economic Growth in China-Based on LMDI Decomposition Method. Economic Survey, No. 5, 18-27.

[11] Wu, Y. (2006) R\&D and Productivity: An Empirical Study Based on Chinese Manufacturing Industry. Economic Research, No. 4.

[12] Pang, W. and Han, X. (2010) An Empirical Study on the Relationship between R\&D and Regional Economic Growth in Colleges and Universities. Technology Economics, 29, 30-36.

[13] Peng, J. and Zhang, J. (2007) Empirical Analysis of China's R\&D Input Effect Based on Dynamic Panel Data Model. Systems Engineering, 25, 47-52.

[14] Cao, Z., Zeng, G., Zou, L. and Liu, G. (2016) Analysis of the Impact of R\&D Investment Based on Panel Data on Regional Economic Growth. Resources and Environment of the Yangtze River Basin, 25, 208-217.

[15] Yu, L. and Zhang, S. (2014) Research on the Relationship between Regional R\&D Investment and Economic Growth in China Based on Panel Data. Commercial Review, No. 27, 7-9.

[16] Feng, W. (2015) China's R\&D Investment and Economic Growth-An Empirical 
Study Based on Provincial Panel Data. Accounting News, No. 36, 27-31.

[17] Sanderson, M.R. (2013) Does Immigration Have a Matthew Effect? A Cross-National Analysis of International Migration and International Income Inequality, 1960-2005. Social Science Research, 42, 683-697.

https://doi.org/10.1016/j.ssresearch.2012.12.004

[18] Yu, M. and Yu, Z. (2006) Analysis of the Path of the Underdeveloped County Economy Leaping over the "Matthew Effect". North China Finance, No. 6, 42-44.

[19] Liu, J. (2005) The "Matthew Effect" of Human Capital Flow and the Government's Coping Strategies. Economics Research, 28, 69-74.

[20] Wang, S. and Hu, S. (2011) Research on Matthew Effect in China's National High-Tech Zone-Concurrently Discussing the Spatial Layout of National Independent Innovation Demonstration Zone. China Soft Science, No. 3, 97-105. 